Themed Issue: Drug Addiction - From Basic Research to Therapies

Guest Editors - Rao Rapaka and Wolfgang Sadée

\title{
Hallucinogen Actions on 5-HT Receptors Reveal Distinct Mechanisms of Activation and Signaling by $\mathbf{G}$ Protein-coupled Receptors
}

Submitted: August 5, 2005; Accepted: September 22, 2005; Published: January 6, 2006

\section{Harel Weinstein ${ }^{1}$}

${ }^{1}$ Department of Physiology and Biophysics, and Institute for Computational Biomedicine, Weill Medical College of Cornell University, New York, NY 10021

\begin{abstract}
We review the effect of some key advances in the characterization of molecular mechanisms of signaling by $\mathrm{G}$ proteincoupled receptors (GPCRs) on our current understanding of mechanisms of drugs of abuse. These advances are illustrated by results from our ongoing work on the actions of hallucinogens on serotonin (5-HT) receptors. We show how a combined computational and experimental approach can reveal specific modes of receptor activation underlying the difference in properties of hallucinogens compared with nonhallucinogenic congeners. These modes of activationthat can produce distinct ligand-dependent receptor statesare identified in terms of structural motifs (SM) in molecular models of the receptors, which were shown to constitute conserved functional microdomains (FM). The role of several SM/FMs in the activation mechanism of the GPCRs is presented in detail to illustrate how this mechanism can lead to ligand-dependent modes of signaling by the receptors. Novel bioinformatics tools are described that were designed to support the quantitative mathematical modeling of ligand-specific signaling pathways activated by the 5-HT receptors targeted by hallucinogens. The approaches for mathematical modeling of signaling pathways activated by 5-HT receptors are described briefly in the context of ongoing work on detailed biochemical models of 5-HT2A, and combined 5-HT2A/5-HT1A, receptor-mediated activation of the MAPK 1,2 pathway. The continuing need for increasingly more realistic representation of signaling in dynamic compartments within the cell, endowed with spatio-temporal characteristics obtained from experiment, is emphasized. Such developments are essential for attaining a quantitative understanding of how the multiple functions of a cell are coordinated and regulated, and to evaluate the specifics of the perturbations caused by the drugs of abuse that target GPCRs.
\end{abstract}

Corresponding Author: Harel Weinstein, Department of Physiology and Biophysics, Box 75, Weill Medical College of Cornell University, 1300 York Avenue, New York, NY 10021. Tel: (212) 746-6358; Fax: (212) 746-8690; E-mail: haw2002@med.cornell.edu
KEYWORDS: molecular modeling, molecular dynamics simulations, membrane proteins, signaling, mathematical modeling, bioinformatics tools

\section{INTRODUCTION}

The rapid advances in the characterization of molecular mechanisms of signaling by $G$ protein-coupled receptors (GPCRs) have enhanced the understanding of mechanisms of drugs of abuse. In particular, the recognition that the translation of intra-receptor mechanisms of activation into intracellular signaling through protein-protein interactions can take diverse forms that are ligand-dependent, is beginning to explain the special properties exhibited by drugs of abuse targeting this type of receptors. This relation is illustrated here by recent results from our ongoing work on the actions of hallucinogens on serotonin receptors, which are members of the rhodopsin-like GPCR family. The findings are reviewed briefly in the context of broader advances in understanding GPCR signaling to clarify the effect on the emerging understanding of cellular mechanisms of the hallucinogenic drugs of abuse that target these receptors.

A very recent review of the structures, pharmacology, and neurophysiology of hallucinogens provides a thorough and thoughtful analysis of the current information and understanding regarding the mechanisms underlying hallucinogen action. ${ }^{1}$ The review illustrates as well how many of the fundamental questions regarding these mechanisms remain unanswered, despite the abundance of information available in the literature from work at all the levels accessible to physiological, pharmacological, and behavioral approaches. The understanding of the involvement of the 5-HT2 receptors targeted by the hallucinogens in these mechanisms, and the molecular and structural requirements for the function of these GPCRs in cellular signaling, are equally incomplete.

To change this situation, we have undertaken a coordinated collaborative effort that brings together experimental and computational approaches. The research effort is supported by the National Institute on Drug Abuse (Bethesda, MD) and combines quantitative computational and experimental approaches in the mechanistic investigation of hallucinogenic 
drug action of compounds in various structural classes including (1) indolealkylamines (eg, the hallucinogenic N,N-dimethyltryptamine); (2) ergolines (eg, D-LSD); and (3) phenylethylamines and phenylisopropylamines (eg, mescaline, DOI) (for reviews see Nichols, ${ }^{1}$ Gresch et al, ${ }^{2}$ and Aghajanian and Marek $^{3}$ ) In the portion of this multifaceted work that is reviewed briefly below, we emphasize the information elicited from the computational modeling and simulations of mechanisms that can discriminate the actions of hallucinogens on the GPCRs in comparison to activation by nonhallucinogenic congeners. The aim of this quantitative modeling is to reveal the molecular details of the manner in which the hallucinogens trigger the mechanistically related subcellular elements that are responsible for their special properties. This type of information is tested, validated, and enhanced by the experimental component of the complete research program, and the insights are directed as well to the design of appropriate therapeutic measures.

The computational structure-function studies and simulation approaches use 3-dimensional (3-D) models of the receptor molecules and their interactions with ligands. Specific structure-based approaches have evolved for this purpose. ${ }^{4,5}$ To enable the study of downstream signaling following ligand-receptor interaction, we have also elaborated larger scale models of GPCR functional entities, ranging from models of GPCR oligomerization, ${ }^{6-8}$ to macromolecular interaction complexes with scaffolding proteins such as PDZ domains. ${ }^{9-11}$ In addition, the newest type of investigation of hallucinogen mechanisms briefly described here aims to integrate the inferences and insights resulting from the studies at the discrete molecular level, into quantitative mechanistic models of signaling pathways in the cell. ${ }^{12-15}$ Such an integrative approach is especially advantageous for the type of multi-disciplinary studies required to understand the mechanisms of drugs of abuse, because the computational studies must be combined with experimental efforts that are performed at several levels of organization (or "scales"). These scales cover the range from molecular and cellular aspects (eg, of signaling by hallucinogens and other ligands of the 5-HT receptors) to the integrated neurophysiological level, and whole animal behavior (eg, see range covered in ${ }^{16-21}$ ). The power of the integrative approach lies in the ability to address complete functional systems in which the effects of drugs of abuse are expressed. Examples of such whole systems that can now be modeled and understood quantitatively are the cellular signaling pathways and networks. This is made possible by new data management tools and computational approaches developed by us and others. ${ }^{13-15}$ The quantitative modeling of signaling mechanisms can generate new mechanistic hypotheses that are suitable for experimental verification at the integrated system level (cell, tissue, organ) that is most pertinent to drug action. Our work discussed below provides specific illustrations of the success of such closely considered interactions and synergy between computational developments and experimental probing of the receptor systems (the combined approach).

\section{THE SYNERGY BETWEEN THE COMPUTATIONAL MODELING AND EXPERIMENTATION}

Briefly summarized, the combined approach comprises the following stages:

\section{3-D constructs of molecular models are devel-} oped $^{4,22}$ and probed computationally in simulations of mutagenesis and structural perturbation, ${ }^{23}$ in order to address characteristics of different states of the receptor molecules that relate to activation, ${ }^{18}$ including oligomerization. 7,8

2. The 3-D models serve in computational simulations of functional mechanisms involving structural rearrangements (eg, ligand-induced), or interactions in the signaling cascade, such as

- dimerization,,$^{7,8}$

- involvement in specific interactions with adaptor proteins such as PDZ-domains, ${ }^{10,11}$ and

- triggering of signaling pathways. ${ }^{15}$

These computational studies generate and/or probe mechanistic hypotheses regarding structural changes involved in the various states of the receptors and their signaling properties, for both wild type (WT) and mutant constructs. They are discussed in the subsequent section in light of the results from the cognate experimental studies in step (3) of the combined approach.

3. The activity of the corresponding constructs is measured in a variety of assays, including

- evaluation of pharmacological properties ${ }^{23}$ and degrees of constitutive activity of the GPCRs defined by various measurable end points, ${ }^{18,24}$

- measurement of nature and extent of dimerization established in experiments ranging from co-IP to cross-linking, and including FRET/BRET, etc, ${ }^{25-29}$

- characterization of ligand-specific signaling pathways, ${ }^{19}$ and

- creation of transgenic animals bearing the constructs to identify behavioral consequences. ${ }^{20,30}$

Recent progress in the development and application of the combined computational and experimental protocol is illustrated in the following sections for (1) intramolecular mechanisms triggering differential modes of ligand-dependent 
activation of GPCRs, and (2) the management of quantitative signaling data for modeling of cellular signaling pathways.

\section{INTRAMOLECULAR MECHANISMS OF LIGAND-DEPENDENT RECEPTOR ACTIVATION}

\section{Structural Motifs Acting as Functional Microdomains in G Protein-coupled Receptors}

A key element in the development of a structure-based insight about the intramolecular mechanisms of liganddependent GPCR activation was our early observation that it is possible to parse the receptor structure into specific regions identified as structural motifs (SM) acting as (often conserved) functional microdomains (FM) (SM/FMs). Especially noteworthy here is that the crystal structure of rhodopsin confirmed the structural predictions regarding the key SM/FM that we obtained from the molecular models, and the functional properties of the SM/FMs we defined coincided with inferences from the crystal structure and were in agreement with the mechanisms suggested from molecular modeling and simulations of GPCRs in the rhodopsin-like family. 5,31
The identification of conserved motifs in the structures of rhodopsin-like GPCRs that create microenvironments with special importance for the function of the receptor was an early consequence of the model-informed studies we undertook in the collaborative effort with several experimental laboratories. These motifs were shown to be sufficiently conserved in structure and function to merit a specific designation, and therefore we described them as SM/FMs in several different GPCRs. ${ }^{5,17,18,24,32-34}$ The $\mathrm{SM} / \mathrm{FMs}$ include, for example, the "ionic lock of the arginine cage", which we described in these publications and has subsequently been confirmed for many other GPCRs. ${ }^{35-44}$

The NPxxY motif conserved in TM7 of the rhodopsin-like GPCRs (including the 5-HT2 subtypes) is an SM/FM involved in receptor activation mechanisms, as demonstrated by our recent findings of the "locked-on" phenotype regulated through this motif. ${ }^{18}$ Figure 1 summarizes some of the findings illustrating the effects of agonists and inverse agonists on the activity of the WT receptor, compared with one of the constitutively active constructs $(\mathrm{Y} 7.53 \mathrm{C})$ and the "locked-on" mutant Y7.53N. (Note the high basal activity

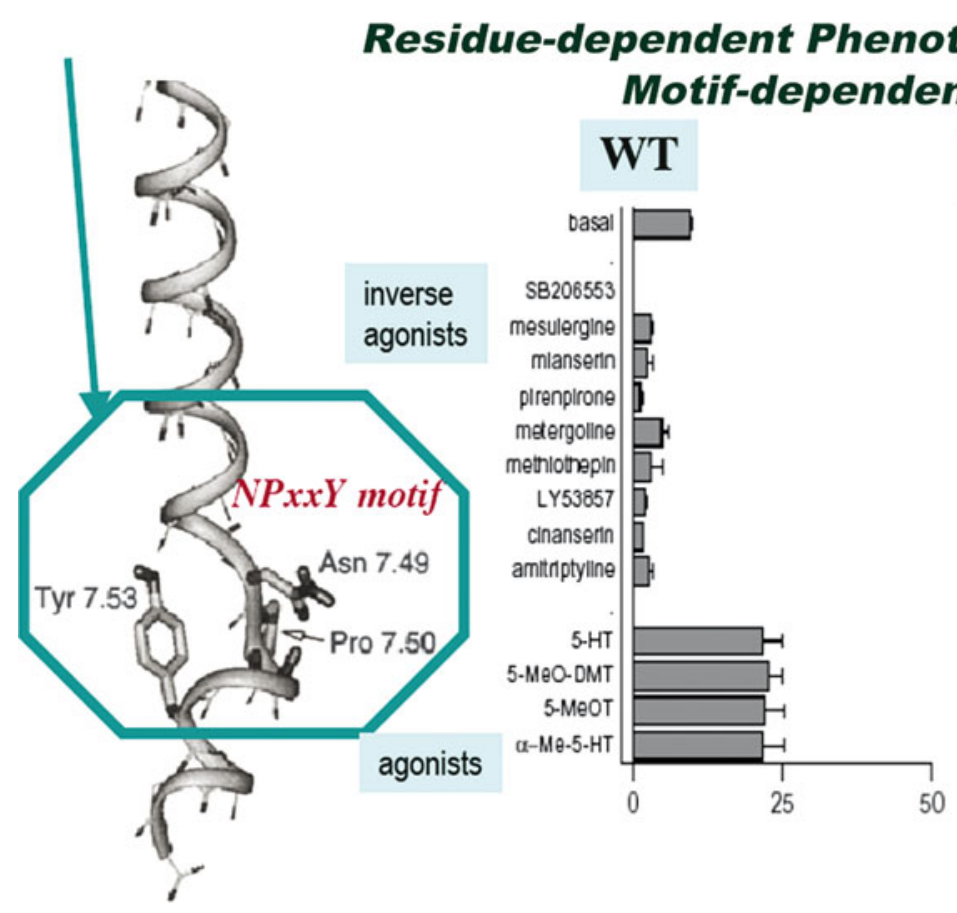

types Reveal a Motif-dependent activation mechanism

"Conserved Helix 7 Tyrosine Acts as a Multistate Conformational Switch in the 5-HT2C

Receptor: Identification of a Novel "Locked-on" Phenotype and Double Revertant

Mutations"

C. Prioleau, I.Visiers, B.J. Ebersole, H. Weinstein and S.C. Sealfon-
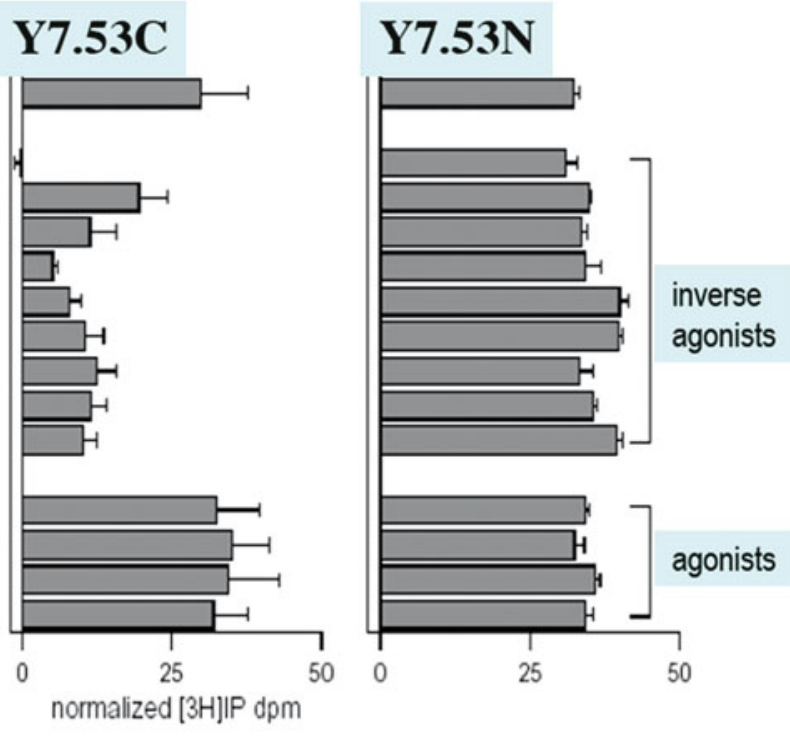

JBC 2002, 277:36577-36584

Figure 1. Data illustrating the functional role of Y7.53 in the NPxxY motif: Different activated states of the 5-HT2C receptors are produced by mutations at the 7.53 locus. The $\mathrm{Y} 7.53 \mathrm{C}$ mutation produces a canonical constitutively activated phenotype, characterized by increased basal activity compared with WT, reduction of the basal activity by various inverse agonists, and activation by various agonists. In contrast, the constitutive activity of the Y7.53N mutant is shown to be irreversible (by any of the inverse agonists), and various agonists are unable to activate further the receptor, which appears locked in an "on" state. 
of the mutants and the ability of the inverse agonists to reduce it for the Y7.53C, but not Y7.53N construct). Of importance, we showed through the identification of a "revertant" mutant phenotype ${ }^{18}$ that this SM/FM connects to Helix 8 of the GPCRs. This connection through the direct interaction of residues at positions 7.53 and 7.60 is highlighted schematically in Figure 2 using representations of the rhodopsin structure. ${ }^{45-49}$ The direct interaction of the NPxxY motif with Helix 8 is likely to be very significant in regulating the interactions of the $\mathrm{C}$-terminal end of the GPCRs with various other cellular components involved in signaling (eg, the PDZ domains ${ }^{10,22}$ ). Like the other $\mathrm{SM} / \mathrm{FM}$ we described, the functional properties of the NPxxY motif have been validated in other receptors as well, ${ }^{50}$ including Rhodopsin. ${ }^{49}$

Another key SM/FM motif, which we were the first to identify as being involved in GPCR activation, triggers the regulation of the "ionic lock" through a series of specific structural rearrangements in the upper (more extracellular) end of the GPCR molecule. This SM/FM comprises the cluster of aromatic residues in TM6 surrounding the conserved Trp6.48, and straddling the conserved Pro6.50. [Note that we are using throughout the generic numbering system for GPCR residues defined initially in Ballesteros and Weinstein ${ }^{51}$ and subsequently adopted widely in the relevant literature]. This motif, which in the 5-HT2A receptor comprises residues F6.44(332), W6.48(336), and F6.52(640) can vary somewhat in composition in different receptors, depending on the nature of the ligand. But these variations preserve the steric properties that can trigger the rearrangement of the other aromatic residues in the SM/FM in the manner of a "toggle switch" 4 that connects the ligand binding event to the rearrangements in the receptor structure leading to activation. The mechanism of activation, simulated in detail as reviewed by Visiers et $\mathrm{al}^{4}$ and Filizola et $\mathrm{al}^{5}$ explains the role of the central residue in the SM/FM W6.48, which was proposed much earlier by the Sakmar Lab (Lin and Sakmar ${ }^{52}$ ) to undergo a conformational rearrangement in the process of rhodopsin activation by light. The toggle switch mechanism of GPCR activation has now been incorporated in current accepted views of rhodopsin-like receptor function. $5,31,35-39,43,44,53-57$

Of importance, the modeling suggested that the ability to trigger this toggle switch determines the efficacy of a ligand. Since the position of a ligand in the binding site should affect its interaction with the aromatic cluster, the ligands

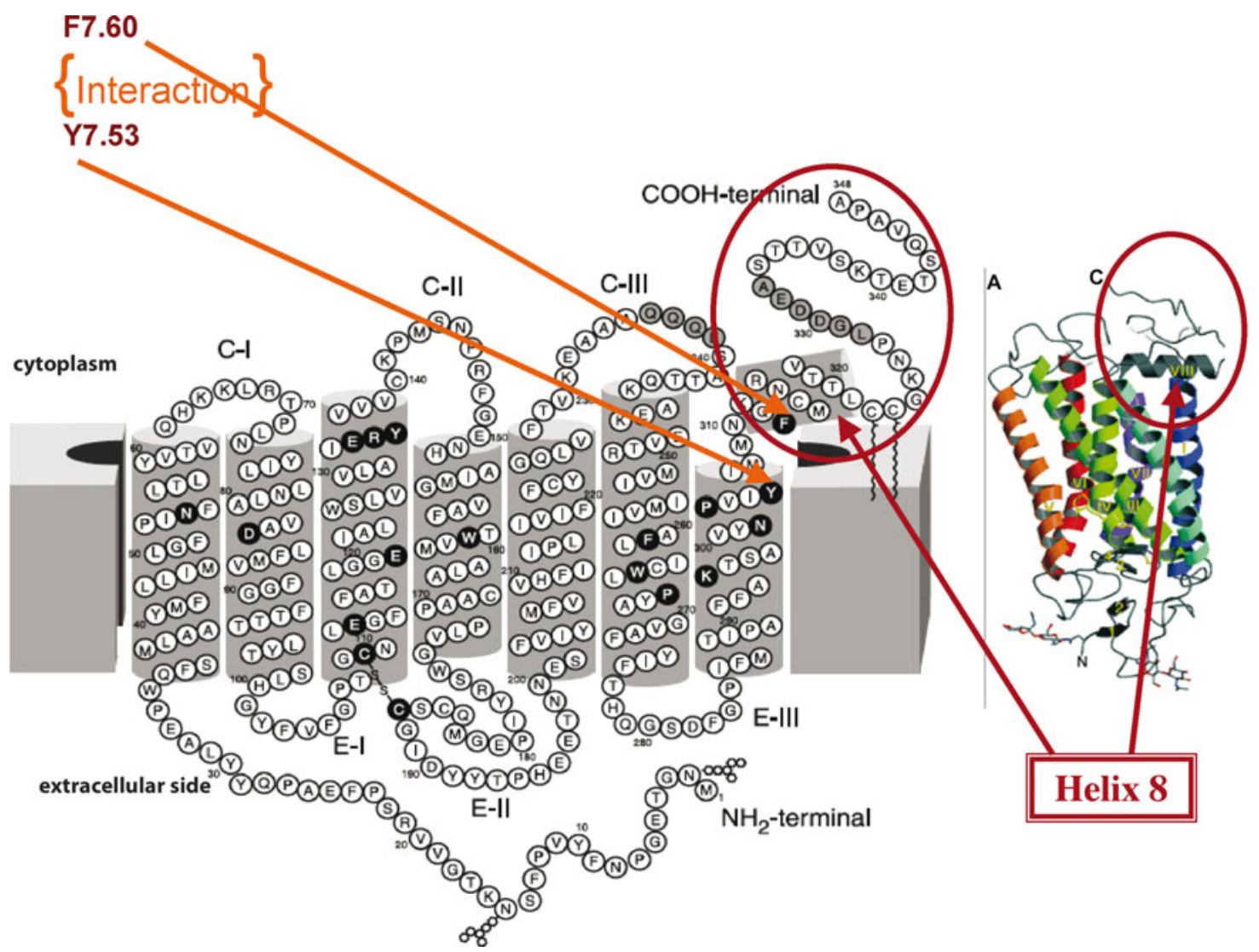

Figure 2. The protein-protein interaction interface between a GPCR and its signaling environment is regulated by intramolecular interactions involving the NPxxY motif: The interaction between Y7.53 and the F7.60, which is in Hx8, controls the position of the helix and the C-terminal. This can regulate the interaction interface between the GPCRs and other proteins in the signaling cascade (eg, PDZ domains). The structural context is illustrated for the crystal structure of Rhodopsin. ${ }^{45}$ 
will differ in the extent to which they can affect the toggle switch. As described in the following section, we had shown that even ligands differing little in chemical structure can adopt different positions in the receptor binding pocket, so that this detailed modeling identifies a structural mechanism for ligand-dependent mode of receptor activation. Notably, in the 5-HT2AR model, the compounds with hallucinogenic properties appear to adopt a very different position in the binding pocket compared with nonhallucinogenic congeners in the same family owing to the bulky substitutions of the cationic amine moiety in the hallucinogenic compounds, specifically 5-HT vs N,N-dimethyl congeners such as psylocin, or vs LSD. ${ }^{23}$ While this is not likely to be the only source of difference in ligand-dependent conformations of the receptor produced by hallucinogens, it is a structurally explicit prototype for the concept of ligand-dependent functional selectivity. ${ }^{58-61}$

\section{Hallucinogens and the Different Modes of $G$ Protein-coupled Receptor Activation}

The central working hypothesis that has emerged from our sustained investigation of the GPCR targets of hallucinogens attributes the hallucinogenic potential of certain compounds to the involvement of their structural elements in specific modes of interaction with the receptor, which produce distinct molecular mechanisms of receptor signaling. The hallucinogens are thus proposed to interact with the receptor molecules in a special manner that elicits, through these distinct interactions, a set of structural and dynamic receptor responses (including protein-protein interactions such as oligomerization, as well as selective PDZ-domain binding) that differ from those produced by other ligands, such as congeneric nonhallucinogens. This central hypothesis led to the investigation of discriminant factors responsible for the special properties underlying the effects of hallucinogenic drugs of abuse on the receptor molecules, and in particular those that result in triggering distinct signaling pathways. The discriminant actions of hallucinogens are of added interest because they can reveal generalizable concepts of ligand-specific receptor function, ${ }^{60-62}$ and the inferences should be directly applicable to many other drugs of abuse mechanisms. The elements of these discriminant actions of the ligands on GPCRs include:

1. the modes of receptor response (conformational rearrangements and stabilization of activated states) responsible for protein-protein interactions ranging from oligomerization to interactions with scaffolding proteins (eg, PDZ domains), and

2. the relation to the selectivity and efficiency of signaling of (a) such conformational rearrangements, and (b) the resulting association/dissociation of protein-protein interactions (produced distinctively by the binding of this class of ligands).

Given the ability we developed to describe GPCR function in terms of SM/FMs, we sought first to reveal the distinct ligand-receptor interaction properties of such motifs. The involvement of the SM/FMs in giving rise to distinct receptor responses is emphasized by our findings discussed in the previous section, regarding the role of ligand orientation in the measurable receptor response. These insights emerged from modeling and computational simulations ${ }^{16}$ involving the Ser3.36(159)Ala mutation in the 5-HT2AR. The results show that 5-HT2AR agonists that have unmodified cationic amine side chains interact with S3.36 in TM3, whereas those with substituted amines - such as the tryptaminebased hallucinogens Psylocin and N,N-dimethyl-tryptamine-are prevented from this interaction by steric repulsion. Surprisingly, this slight difference in mode of binding and orientation in the binding pocket was found experimentally (in the collaboration with the lab of Stuart Sealfon, Mount Sinai School of Medicine) to create significant differences in the pharmacological efficacy (relative to 5-HT). Similarly, alkyl substitution of the indole N1-amine in 5-HT and congeners (including LSD), which interacts with Ser5.46, reduced efficacy more markedly at the WT than at the Ser5.46Ala mutant receptor. Computational modeling of binding pocket interactions of ligands with WT and mutant-receptor constructs demonstrated how the Ser3.36 and Ser5.46 interactions serve to modify the agonist's favored position in the binding pocket. This provides a striking illustration of differential modes of binding leading to differential outcomes of receptor activation by ligands that exhibit only slight structural differences and constitutes a fundamental new realization in our understanding of GPCR function.

The definition of the SM/FMs provided a specific structural context for the functional implications of ligand-dependent modes of receptor activation. Thus, using the combined approach of experiment and simulation we showed how the differential ligand positioning by one of the binding pocket components, is "sensed" by yet another SM/FM - the aromatic cluster in $\mathrm{TM}^{63}$ that functions as the toggle switch described in the preceding section. The dynamics of the local rearrangements in the structure of the aromatic cluster, which can be triggered by ligand binding in the pocket and interaction with the F6.52 sensor, were probed with computational simulations in a 3-D model of the serotonin 5HT2AR. ${ }^{4,5}$ The computed rearrangement of the aromatic cluster $^{64}$ in response to ligand binding, and the subsequent conformational change induced at the P6.50 kink, are the likely trigger for the transition from the inactive form to the active state of the receptor. The quantitative simulation details 4,65 support the hypothesis that the position of the agonist in the receptor is influenced by specific interactions 
in TMs 3 and 5 and determines the degree of receptor activation by agonist through the conformational rearrangement mechanism involving the SM/FM in TM6. This coupling of SM/FM-mediated mechanism of ligand-specific receptor activation is central to understanding the manner in which drugs of abuse, such as the hallucinogens, acquire and express their special properties. Moreover, such mechanistic inferences have recently been shown to explain findings in other GPCRs ${ }^{54,55,66}$ including those targeted by other drugs of abuse, such as the cannabinoids. ${ }^{67}$

\section{Dynamic Elements of G Protein-coupled Receptor Signaling Mechanisms: New Insights and Methodological Imperatives for Their Investigation}

Computational modeling studies seeking mechanistic insight into signaling components from quantitative simulations require reliable structural models of the receptors. For most, albeit not all, studies, these models must include responsibly constructed and appropriately modeled loops connecting the transmembrane (TM) segments. In a previous study, ${ }^{68}$ we discussed the basis for this latter conclusion regarding the loops. The essential role for a rigorous representation of the loops was illustrated as well by results from our earlier work on the second intracellular loop (IL2) in the 5-HT2CR. ${ }^{69}$ The study was performed to gain insight into the specific role of the intracellular loop segment following the conserved ArgAspTyr (DRY) motif and the "arginine cage" SM/FM in TM3 (see Structural Motifs Acting as Functional Microdomains in GPCRs). Specifically, we addressed the functional consequences of the surprising process of RNA editing discovered for the 5-HT2C receptor gene. ${ }^{70,71}$ These adenosine-to-inosine RNA editing events for 5HT2C receptors were shown to result in sequence alterations at positions 156,158 , and 160 in the IL2 region. The edited receptor isoforms were shown to exhibit various extents of changes in their pharmacological and physiological phenotypes. To identify the molecular mechanism of these pharmacological effects of editing, we explored the conformational properties of the edited IL2 in comparison with the unedited construct, using an early form of our loop-structure-prediction methodology (we subsequently described an even more powerful and accurate version of the method ${ }^{72,73}$ ).

The calculations showed that a modification of a small element in the sequence (ie, a change from the unedited sequence I[156]RN[158]PI[160]EHSRFN [termed INI] to VRGPVEHSRFN [termed VGV]) causes a significant change in the preferred conformational orientation of the loop. A direct result is a significant change in the interaction surface of the 5-HT2C receptor with the cognate G-protein. ${ }^{69}$ The quantitative analysis showed that parallel changes in the observed pharmacological properties of the modified (VGV) receptors are attributable directly to the effect that this change in the interaction surface has on the formation of the GPCR signaling complex with G-proteins.

The major lesson from these results was the high sensitivity of the signaling system to even relatively small changes in the interaction surface presented to other intracellular loops, and/or the G-protein. They highlight the relation between intramolecular rearrangements caused by ligand-induced activation of the GPCRs, and the manner in which the activation signal is propagated. Specifically, the structural consequences of ligand binding determine the mode of protein-protein interactions along the signaling cascade of the receptors. The regulation of such GPCR-signaling protein interaction surfaces by ligand-related structural changes in the receptor molecule, such as those illustrated above for the NPxxY motif (see Figure 2), continues to be the subject of intensive studies in our laboratory.

The importance of the dynamic structural changes in the mechanisms of ligand-dependent GPCR activation points to important methodological conclusions concerning the appropriate approaches to modeling of detailed molecular mechanisms of GPCRs. In particular, the immediate environment of the receptor has emerged as an essential element in the representation and correct modeling of GPCRs for computational simulations (see Figure 3). To achieve reliable results, the molecular models of the receptor structures used in computational simulations have to be complete and must include (1) the TM-connecting loops, constructed with appropriate structure-prediction methods and calculated explicitly, ${ }^{65,68,72}$ and (2) the complex environment of the molecular system composed of protein/ligand/waters (ie, bulk water and the phospholipid bilayer).$^{68}$ Such molecular constructs (Figure 3) are then suitable for the examination

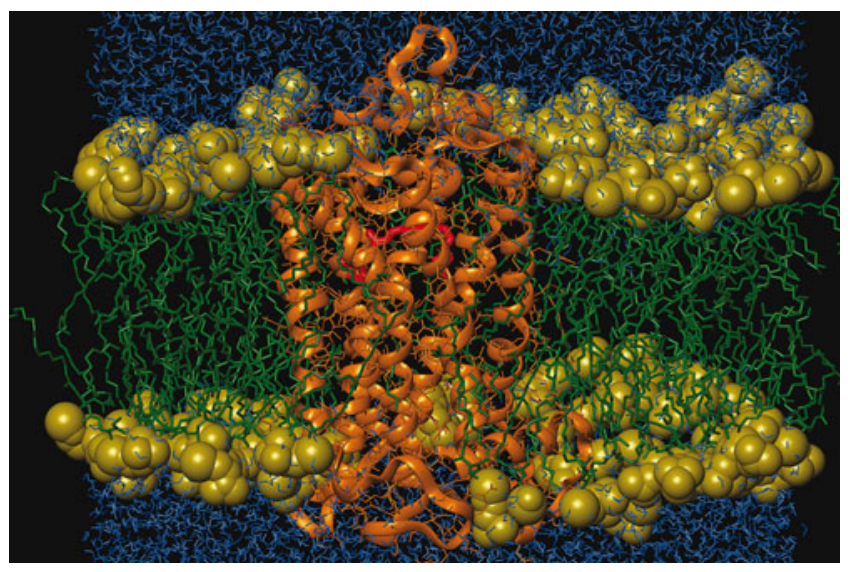

Figure 3. Molecular model of the complete GPCR (rhodopsin) in an atomistic representation of its environment. The protein is rendered in gold color, with the retinal in red. The lipid portion of the phospholipids is shown in green, and their head groups are rendered in yellow. The surrounding water molecules are rendered in blue. 
of interactions of various ligands from the results of extensive simulations of ligand-receptor complexes with the monomeric receptor structures, challenged by perturbations and control experiments. Clearly, any attempt to understand the mechanisms and effects of GPCR dimerization must take into account the environment. For discrete molecular representations of the membrane environment, it is necessary to carry out careful calibrations of the model. ${ }^{74}$ Based on the evidence that rhodopsin reconstituted in artificial membranes is functional, ${ }^{75}$ we use a hydrated patch of 1-Palmitoyl-2-oleoyl-sn-glycero-3-phosphocholine (POPC) lipid bilayer membrane to simulate the appropriate environment for receptor dimers. The size of a lipid unit cell that could accommodate a receptor dimer was calibrated with the dimer configuration with TM4 and TM5 at the interface recently proposed for rhodopsin, ${ }^{76}$ which includes both TMs and loops regions. Our studies ${ }^{74,77,78}$ have shown the appropriate distance between the solute protein and a simulation box boundary to correspond to $\sim 4$ to 5 layers of lipid molecules. According to this criterion, the unit cell was generated by duplicating and truncating a fully equilibrated POPC patch. ${ }^{79}$ Based on the average size of a rhodopsin dimer $(85 \times$ $50 \AA$ ), as calculated from the oligomeric complex (PDB ID code: $1 \mathrm{~N} 3 \mathrm{M}$ ), an orthorhombic lipid unit cell was selected for such studies, with $\mathrm{a}=160 \AA, \mathrm{b}=124 \AA$, and $\mathrm{c}=98 \AA$. Pre-equilibrated water molecules were added at the edges of both lipid patches in the direction of the membrane normal, resulting in a system with 640 lipid molecules and 36836 water molecules, for a total of 143788 atoms (with the Rhodopsin dimer in this equilibrated POPC bilayer unit cell, the system size went up to 148252 atoms).

The equilibration of the POPC bilayer unit cell using GROMACS with lipid parameters ${ }^{80}$ and simple point charge (SPC) water model was performed after energy minimization in several cycles of steepest descent followed by conjugate gradient (converged at $100 \mathrm{~kJ} \cdot \mathrm{mol}^{-1} \cdot \mathrm{nm}^{-1}$ ). These simulations are performed with semi-isotropic coupling, with the pressure, at 1.0 bar, coupled separately to the $x y$ plane and $\mathrm{z}$ directions. Temperature is controlled with the weak coupling scheme of Berendsen, coupling each phase of lipid and water separately with a $310 \mathrm{~K}$ bath. The particle mesh Ewald (PME) summation algorithm is applied, with interpolation order set to 6 and maximum grid spacing for the fast Fourier transform (FFT) set to $0.12 \mathrm{~nm}$. The Coulomb cut-off, and cut-off for the short-range neighbor list were both set to $0.9 \mathrm{~nm}$, and a 1.2-nm Lennard-Jones cutoff was applied. The size of the system caused the potential energy of the system to reach a stable plateau only after 1-nanosecond simulation time; the converged area of the xy plane per lipid $\left(61.8 \AA^{2}\right)$, and the deuterium order parameter profile taken over the last 1 nanosecond of the trajectory were both close to the experimentally determined values. ${ }^{81}$
In view of the complexity of the intramolecular rearrangements produced by distinct effects of various ligands, and the delicate balance of protein-protein interactions involved in the signal transduction mechanism by GPCRs, there can no longer be any doubt that the modeling of such systems must reach a high level of physical realism in order to be useful for structure-function studies, as discussed and illustrated specifically in Mehler et al. ${ }^{68}$ Unfortunately, such methodological imperatives are all too often neglected in computational attempts to describe structure-function relations of GPCRs. Not surprisingly, this neglect leads invariably to disappointingly wrongheaded inferences that are evident in publications on this subject. Unfortunately, it is not always recognized immediately how erroneous some of the inferences can be if they are reached from such flawed studies. Thus, GPCR models with loops attached to the TM region using methods other than careful structure prediction (eg, from the often used spurious homologies with short segments that are fished randomly from the Protein Data Bank, or from the generation of loop segment structures using weak methods such as energy minimization) produce misleading models, which lead to incorrect conclusions about important mechanisms such as the involvement of loops in ligand binding, or oligomerization. Similarly, bad approaches to structure-function modeling of GPCRs include energy-based minimization and/or dynamics simulations that are mistakenly performed in vacuum (using any variety of fixed-value "dielectric constants"). For these membrane proteins, the approach is flawed, because by neglecting the 3 different phases in which the loops and TM region are imbedded, the structures are subjected to artifacts (eg, the interaction of polar residues from the loops), with side chains in the TM regions. This type of spurious interaction in vacuum would have been prevented by a correct representation of the environment composed of the lipid, phospholipids head groups, and the surrounding aqueous medium. In the absence of appropriate modeling of the environment, the loops "collapse" toward the TM region and produce unacceptable artifacts.

\section{MODELING G PROTEIN-COUPLED RECEPTOR ACTIVITY AT THE SYSTEMS LEVEL}

Signaling pathways, such as those triggered into action by ligands binding to the GPCRs, constitute the fundamental mechanisms underlying cell physiology and its connection to the environment. In turn, these signaling pathways interact, and they are interconnected in the cell's signaling networks that provide the mechanisms of regulation for most cellular functions. Not surprisingly, signaling pathways, networks, and the underlying molecular mechanisms are the focus of intense current research that encompasses both experimental and theoretical studies. ${ }^{12,13,82-85}$ To integrate the results of our studies on the receptor mechanisms of 


\section{The AAPS Journal 2006; 7 (4) Article 85 (http://www.aapsj.org).}

hallucinogens, with the current understanding of such signaling pathways, we are developing specialized computational tools, and quantitative models of signaling cascades triggered by receptor activation.

The "models of signaling pathways" discussed in this section are distinct from the molecular models of receptors and protein-protein complexes that were the subject of the previous sections. A useful definition of the signaling models states: "A model, in this language, is simply a collection of hypotheses and facts brought together in an attempt to understand the [cellular] phenomenon...the facts and hypotheses are composed of the molecular species and the biochemical or electrophysiological transformations that are presumed to underlie the cellular events."13 Therefore, these models provide a formal framework for understanding the mechanisms underlying a particular event in the cell. The models consist of the molecular species participating in the event, and the mechanisms (eg, protein-protein interactions, phosphorylation reactions) and diffusion fluxes in a particular compartment of the cell. The quantitative elements comprise the concentrations, locations, interaction rates and transport kinetics of the molecules involved in the event (eg, signaling), and they relate the hypothesized mechanisms to quantitative physico-chemical details. ${ }^{12}$ The models are used in simulations in which the equations are solved as a function of time and initial conditions (see below, section Systems-Level Modeling and Simulation in the Study of Hallucinogen Mechanisms). The quantitative information from these simulations contains the time-dependent changes in concentrations of cell components, and the results of their interactions. We have been able to undertake this work with the support from the Program for Developing Computational and Theoretical Models in Drug Abuse and Addiction at National Institute on Drug Abuse (NIDA).

\section{SigPath-A Comprehensive Information Management System}

The large amount of data used in the modeling effort, as well as the resulting models, must be managed and maintained in a transparent and readily accessible database. The existing examples of bioinformatics databases offer large amounts of information about the parts that constitute an integrated system; they usually specialize in one type of biological entity (eg, gene, transcript, protein, specific classes of proteins). However, the modeling goals prompted us to design a new type of information management system (IMS), the SigPath project. This offers a new type of bioinformatics tool that integrates resources and scientific themes (see detailed description in Campagne et $\mathrm{al},{ }^{15}$ and at the Institute for Computational Biomedicine website. Moreover, SigPath, which is freely available over the Internet (http://www.sigpath.org) both as a Web application and as source code released under the GNU General Public License, connects traditional bioinformatics databases with modeling environments (ie, mathematical modeling and simulation tools, such as Virtual Cell ${ }^{12,86,87}$ ) and acts as a bridge between bioinformatics and computational cell biology resources. The system differs from traditional bioinformatics databases in the following ways: (1) it stores the level of quantitative information needed to support the creation of quantitative models; (2) it organizes information as connected graphs of strongly typed elements of information; (3) it focuses on allowing end-users to manage information directly - see scheme in Figure 4.

The development of SigPath enables us to seek the mechanistic details of hallucinogen activities through the integrative approach that combines findings from computational and modeling studies of interactions among cellular components, with those obtained experimentally. This integration makes it necessary to combine different types of data and information, including structural (eg, mutant constructs) as well as quantitative data (eg, on the concentrations of the components, and their kinetic interaction constants). The example of the activation of the MAPK1,2 pathway by 5-HT2AR ligands, described in the subsequent section illustrates as well the nature of criteria and choices in the development of the SigPath ontology. Thus, when considering the example of cellular compartments, one option is to define the representation of these compartments as contiguous subregions of space. Formally, this data representation choice calls for coding spatial geometries, for instance, as a combination of elementary volume elements (eg, through union and intersection), or as the space enclosed within a surface. However, there is a current paucity of spatial data about 3-D subcellular geometries, and the Virtual Cell tool we used (see below) was designed to work with 2-D geometries (eg, as acquired with various microscopy methods). We plan to extend the SigPath ontology, so that intracellular and extracellular compartments where biological entities have been experimentally observed will be represented by the Compartment class (eg, membrane proteins that are produced in the ER, transfer to the Golgi and then to the plasmamembrane, can be described in this representation), and by the Localized Chemical class that positions the reagents in a specific cellular location (compartment or membrane). Reactions among molecules can then be represented in specific compartments or membranes, or across compartments in realistic 3-D representations that are based on experimental data from imaging at the appropriate level of detail.

\section{Systems-level Modeling and Simulation in the Study of Hallucinogen Mechanisms}

To reveal the discriminant features of the cellular mechanisms triggered by the hallucinogens' actions on the 5-HT2 
The AAPS Journal 2006; 7 (4) Article 85 (http://www.aapsj.org).

Campagne et al., Science STKE 2004(248): p. PL11

http://www.sigpath.org

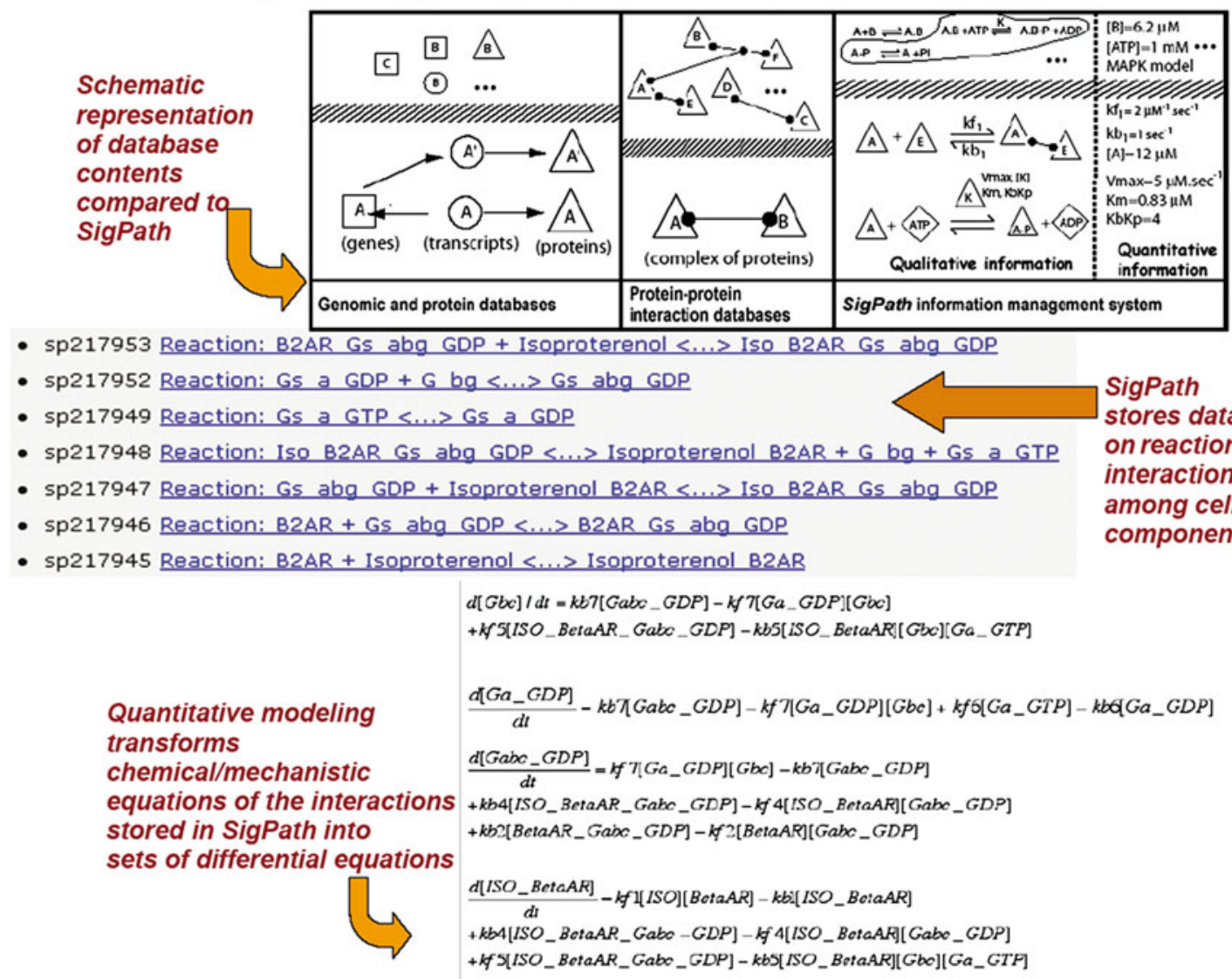

Figure 4. Schematic representations of SigPath ${ }^{15}$ characteristics: SigPath contents compared with traditional databases show the information management characteristics that include detailed reactions among the entries, as well as their quantitative parameters; the stored reaction information is illustrated, with specific identification numbers (sp-id of the form spxxxx, where $\mathrm{x}$ are running numbers) assigned by SigPath; the transformation of the reaction information into ODEs performed through transparent connections to mathematical modeling environments such as VirtualCell. ${ }^{12}$

receptors we studied, we must combine the mechanistic insights at the level of GPCR function, with the growing understanding of signal transduction pathways in the cells. In particular, the application of novel modeling approaches is needed to address the physiological consequences of the signal transduction processes as a series of intracellular interactions in the signal transduction pathways. To this end, we take advantage of bioinformatics tools ${ }^{15}$ as described in the previous section, Sigpath-A Comprehensive Information Management System, and apply the accessible quantitative approaches for cell systems modeling (eg, see ${ }^{12,13,86,88}$ ) to study the structure-function relations of GPCRs in the context of their signaling pathways.

Understanding signal flow from the cell surface requires attention to the signaling events triggered at the receptors and propagated through protein-protein interactions. The schematic representation of a signaling pathway triggered by activation of the 5-HT2AR is shown in Figure 5A. The involvement of the MAPK system in the signaling cascade linking the 5-HT2AR to PLA2 activation has been observed recently ${ }^{89}$ and analyzed in comparison to other signaling modes. ${ }^{90}$ As discussed in illuminating detail in a recent review by Nichols, ${ }^{1}$ signaling of these receptors through Phospholypase C (PLC) $)^{91-94}$ is complemented by apparently independent action in the PLA2 signaling cascade. ${ }^{89,90,95}$ The importance of this pathway was emphasized in the review of hallucinogen mechanisms. ${ }^{1}$ The exciting previous findings about the MAPK1,2 pathway from the Iyengar lab (Bhalla et $\mathrm{al}^{96}$ ) prompted a collaborative study focused on determining if simultaneous activation of the pathways activated through the $5 \mathrm{HT} 1 \mathrm{~A}$ and $5 \mathrm{HT} 2 \mathrm{~A}$ receptors leads to a switching of mitogen-activated protein kinase (MAPK 1,2). A schematic illustration of a possible way in which the signaling pathways triggered by activation of these 2 receptors could communicate in the activation of MAPK1,2 is given in Figure 5B. As shown in the scheme, the putative interaction of the pathways to form a MAPK1,2 activation network triggered in combination by the 25 -HT receptor subtypes is proposed to converge at phospholypaseC-beta (PLCb). The 

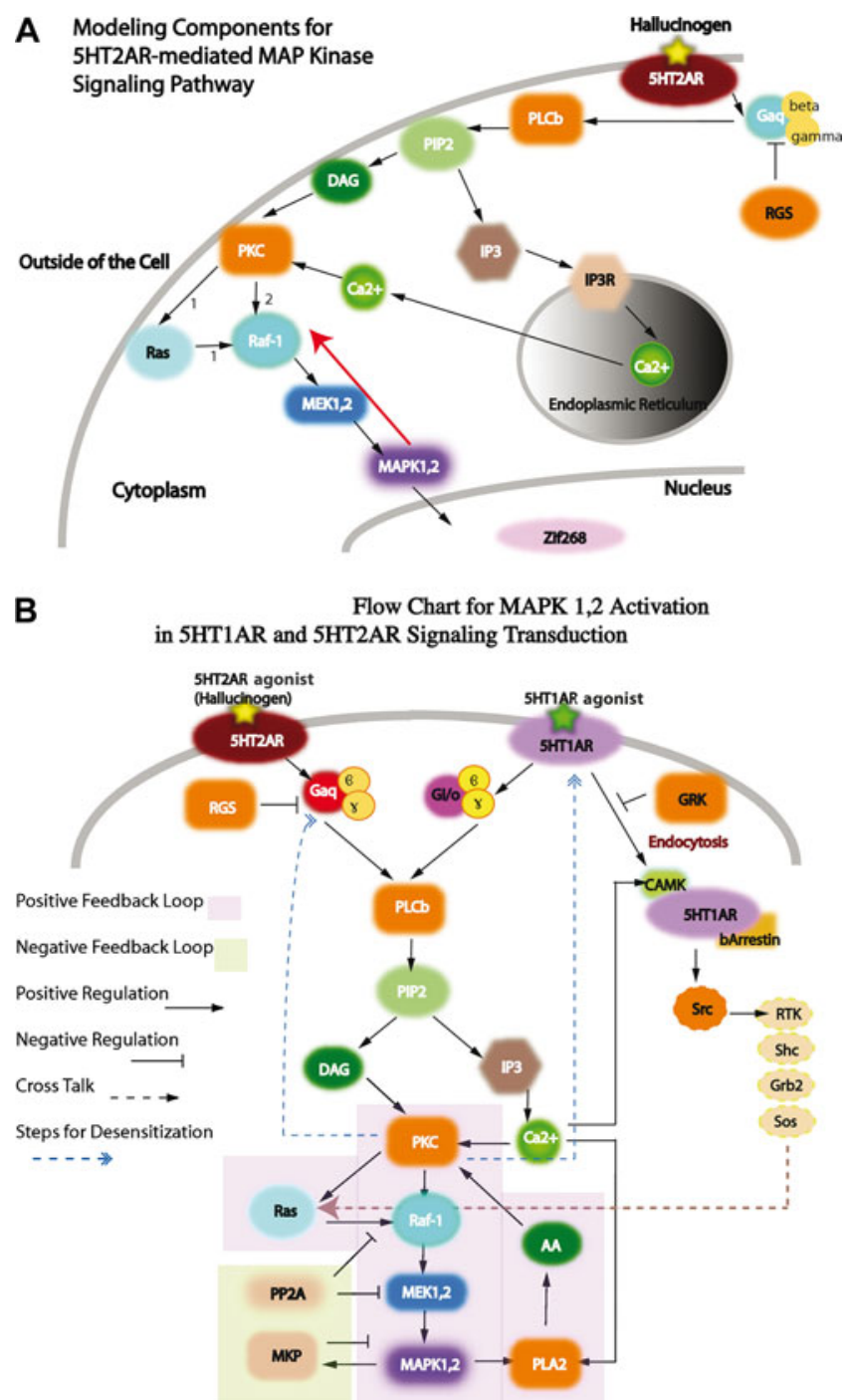

Figure 5. Schematic representations of signaling pathways from 5-HT receptors to the MAPK system. (A) Signaling pathway triggered by activation of the 5-HT2A receptor coupled to G $\alpha$; and (B) A putative combination of signaling pathways activated by ligand binding to both 5-HT2A and 5-HT1 A receptors.

possible intermediates involved in MAPK signaling are known to include PKC, Src and PI-3K, but the overall connectivity is strongly dependent on cell type, and the quantitative details of the signal flow through this pathway are not yet understood fully. In the collaborative studies with the Iyengar lab, Chiung-wen Chang has performed time course experiments of MAPK-1,2 phosphorylation in 2 cell lines, NIH3T3 and COS-7, transfected with 5-HT2A and 5-HT1A receptors individually and together. The preliminary results indicate that cotransfection of 5-HT2A and 5-HT1A receptors in COS-7 cells under stimulation of 5-MT (5-methyoxytryptamine), a general 5-HT1/5-HT2 agonist, produced prolonged activation of phospho-MAPK 1,2 compared with transfection with each of the receptors alone, but of a reduced magnitude. In NIH3T3 cells, prolonged activation of phospho-MAPK 1,2 was observed in cotransfected
5-HT2A and 5-HT1A receptors with treatment of a selective 5-HT2 agonistDOI((+/-)-2,5-dimethoxy-4-iodoamphetamine), which has hallucinogenic properties and elicits the hallucinogenspecific transcriptome fingerprint. ${ }^{19}$

To simulate a detailed biochemical model of 5-HT2A receptor-mediated MAPK1,2 activation, biochemical parameters were obtained from the literature and computations were performed using Virtual Cell. ${ }^{86,87}$ Briefly described, the quantitative modeling (simulation) procedure in Virtual Cell first converts the specified biochemical reaction steps into a system of ordinary differential equations (ODEs) and applies constraints related to mass conservation and pseudo steadystate approximations, before applying numerical solvers to perform the simulations. The quantitative data stored in SigPath is converted automatically to systems of ODE, as illustrated schematically in Figure 4, and conditions are imposed to solve these ODEs: (1) physical barriers are identified within the cellular system, such as the cell membrane, organelle membrane, etc; (2) the location of the reaction species is defined in each physical compartment; and (3) initial conditions are set for species concentrations and reactions, including the rate parameters. The results of the simulations are compared with data from measurements performed on control systems, or available in SigPath and the literature for cognate elements in other studied cell systems $\left(\mathrm{cf}^{88,96-99}\right)$.

The main features of the results (not shown here) are in agreement with quantitative experimental data. Notably, the simulations serve to elucidate the role of the RGS proteins in regulating signaling from the agonist occupied receptor to downstream effectors. It is undoubtedly clear that such studies encounter major bottlenecks in the form of (1) the gathering and curation of the qualitative (pathway) data required for the models, and the quantitative data required for the simulations; and (2) the sheer paucity of such data. These have been considered in the development and population of the SigPath IMS, and in several responsible reviews in the current literature in systems biology. ${ }^{12-14,82,83,88}$ Still, the value of modeling with the available levels of data for both hypothesis testing and experiment design have been considered to remain highly significant. ${ }^{82}$ Ultimately, we expect increasingly more realistic representation of signaling in dynamic compartments within the cell, endowed with spatio-temporal characteristics obtained from experiment. Such models are likely to be increasingly necessary for development of an understanding of how the multiple functions of a cell are coordinated and regulated, and to evaluate the specifics of the perturbations caused by the hallucinogenic ligands of GPCRs.

\section{ACKNOWLEDGMENTS}

The research reviewed here is performed by a very talented group of current and past students and postdoctoral 
The AAPS Journal 2006; 7 (4) Article 85 (http://www.aapsj.org).

associates in the Weinstein lab, too numerous to thank individually, but worthy of very high praise. The longstanding collaboration in bioinformatics with Fabien Campagne at Weill Medical College, and with the experimental labs of Stuart Sealfon and Ravi Iyengar at Mount Sinai School of Medicine, New York, NY, and of Jonathan Javitch, Renee Hen, and Jay Gingrich at Columbia University, New York, $\mathrm{NY}$, is acknowledged with pleasure and gratitude. The work was supported in part by National Institutes of Health (NIH) grants from the National Institute on Drug Abuse (K05DA00060 and P01-DA12923), and by the Institute for Computational Biomedicine (ICB) at Weill Medical College of Cornell University. The computations were performed with the resources of the ICB and the Pittsburgh Supercomputer Center, Pittsburgh, PA, which are gratefully acknowledged.

\section{REFERENCES}

1. Nichols DE. Hallucinogens. Pharmacol Ther. 2004;101:131-181.

2. Gresch PJ, Strickland LV, Sanders-Bush E. Lysergic acid diethylamide-induced Fos expression in rat brain: role of serotonin-2A receptors. Neuroscience. 2002;114:707-713.

3. Aghajanian GK, Marek GJ. Serotonin and hallucinogens. Neuropsychopharmacology. 1999;21:16S-23S.

4. Visiers I, Ballesteros JA, Weinstein H. Three-dimensional representations of $\mathrm{G}$ protein-coupled receptor structures and mechanisms. Methods Enzymol. 2002;343:329-371.

5. Filizola M, Visiers I, Skrabanek L, Campagne F, Weinstein H. Functional mechanisms of GPCRs in a structural context. In: Schousboe A, Bräuner-Osborne H, eds. Strategies in Molecular Neuropharmacology. Totowa, NJ: Humana Press; 2003:235-266.

6. Filizola M, Weinstein H. The study of G-protein coupled receptor oligomerization with computational modeling and bioinformatics. FEBS $J$. In press.

7. Filizola M, Weinstein H. Structural models for dimerization of G-protein coupled receptors: the opioid receptor homodimers. Biopolymers. 2002;66:317-325.

8. Filizola M, Guo W, Javitch JA, Weinstein H. Oligomerization domains in G-protein coupled receptors: insights into the structural basis of GPCR association. In: Devi LA, ed. The G-Protein Coupled Receptor Handbook. Totowa, NJ: Humana Press Inc; 2005.

9. Beuming T, Skrabanek L, Niv MY, Mukherjee P, Weinstein H. PDZBase: a protein-protein interaction database for PDZ-domains. Bioinformatics. 2005;21:827-828.

10. Chang CW, Hassan SA, Weinstein H. Determinants for specificity in binding to the PDZ domain of PICK1. Biophys J. 2004;86:96a.

11. Madsen KL, Beuming T, Niv MY, et al. Molecular determinants for the complex binding specificity of the PDZ domain in pick 1. J Biol Chem. 2005;280:20539-20548.

12. Slepchenko BM, Schaff JC, Macara I, Loew LM. Quantitative cell biology with the Virtual Cell. Trends Cell Biol. 2003;13:570-576.

13. Slepchenko BM, Schaff JC, Carson JH, Loew LM. Computational cell biology: spatiotemporal simulation of cellular events. Annu Rev Biophys Biomol Struct. 2002;31:423-441.
14. Wachman ES, Poage RE, Stiles JR, Farkas DL, Meriney SD. Spatial distribution of calcium entry evoked by single action potentials within the presynaptic active zone. $J$ Neurosci. 2004;24:2877-2885.

15. Campagne F, Neves S, Chang CW, et al. Quantitative information management for the biochemical computation of cellular networks. Sci STKE. 2004;2004:p111.

16. Ebersole BJ, Visiers I, Weinstein H, Sealfon SC. Molecular basis of partial agonism: orientation of indoleamine ligands in the binding pocket of the human 5-HT2A serotonin receptor determines relative efficacy. Mol Pharmacol. 2003;63:36-43.

17. Visiers I, Ebersole BJ, Dracheva S, Ballesteros JA, Sealfon SC, Weinstein H. Structural motifs as functional microdomains in G-protein-coupled receptors: energetic considerations in the mechanism of activation of the serotonin 5-HT2A receptor by disruption of the ionic lock of the arginine cage. Int J Quantum Chem. 2002;88:65-75.

18. Prioleau C, Visiers I, Ebersole BJ, Weinstein H, Sealfon SC. Conserved helix 7 tyrosine acts as a multistate conformational switch in the 5HT2C receptor: identification of a novel "locked-on" phenotype and double revertant mutations. J Biol Chem. 2002;277:36577-36584.

19. Gonzalez-Maeso J, Yuen T, Ebersole BJ, et al. Transcriptome fingerprints distinguish hallucinogenic and nonhallucinogenic 5-hydroxytryptamine $2 \mathrm{~A}$ receptor agonist effects in mouse somatosensory cortex. J Neurosci. 2003;23:8836-8843.

20. Gingrich JA, Ansorge MS, Merker R, Weisstaub N, Zhou M. New lessons from knockout mice: the role of serotonin during development and its possible contribution to the origins of neuropsychiatric disorders. CNS Spectr. 2003;8:572-577.

21. Ebersole BJ, Sealfon SC. Strategies for Mapping the Binding Site of the Serotonin 5HT2A Receptor. In: Iyengar R, Hildebrandt J, eds. Methods in Enzymology. San Diego, CA: Academic Press; 2001.

22. Beuming T, Weinstein H. A knowledge-based scale for the analysis and prediction of buried and exposed faces of transmembrane domain proteins. Bioinformatics. 2004;20:1822-1835.

23. Ebersole BJ, Visiers I, Weinstein H, Sealfon SC. Molecular basis of partial agonism: orientation of indoleamine ligands in the binding pocket of the human serotonin 5-HT2A receptor determines relative efficacy. Mol Pharmacol. 2003;63:36-43.

24. Ballesteros J, Kitanovic S, Guarnieri F, et al. Functional microdomains in G-protein-coupled receptors: the conserved argininecage motif in the gonadotropin-releasing hormone receptor. $J$ Biol Chem. 1998;273:10445-10453.

25. Javitch JA. The ants go marching 2 by 2: oligomeric structure of G-protein-coupled receptors. Mol Pharmacol. 2004;66:1077-1082.

26. Filizola M, Olmea O, Weinstein H. Prediction of heterodimerization interfaces of G-protein coupled receptors with a new subtractive correlated mutation method. Protein Eng. 2002;15:881-885.

27. Filipek S, Teller DC, Palczewski K, Stenkamp R. The crystallographic model of rhodopsin and its use in studies of other G protein-coupled receptors. Annu Rev Biophys Biomol Struct. 2003;32:375-397.

28. Filipek S, Krzysko KA, Fotiadis D, et al. A concept for G protein activation by $\mathrm{G}$ protein-coupled receptor dimers: the transducin/ rhodopsin interface. Photochem Photobiol Sci. 2004;3:628-638.

29. Hoffmann C, Gaietta G, Bunemann M, et al. A FlAsH-based FRET approach to determine $\mathrm{G}$ protein-coupled receptor activation in living cells. Nat Methods. 2005;2:171-176. 


\section{The AAPS Journal 2006; 7 (4) Article 85 (http://www.aapsj.org).}

30. Zhuang X, Masson J, Gingrich JA, Rayport S, Hen R. Targeted gene expression in dopamine and serotonin neurons of the mouse brain. $J$ Neurosci Methods. 2005;143:27-32.

31. Ballesteros JA, Shi L, Javitch JA. Structural mimicry in G proteincoupled receptors: implications of the high-resolution structure of rhodopsin for structure-function analysis of rhodopsin-like receptors. Mol Pharmacol. 2001;60:1-19.

32. Huang P, Li J, Chen C, Visiers I, Weinstein H, Liu-Chen LY. Functional role of a conserved motif in TM6 of the rat mu opioid receptor: constitutively active and inactive receptors result from substitutions of Thr6.34(279) with Lys and Asp. Biochemistry. 2001;40:13501-13509.

33. Flanagan CA, Zhou W, Chi L, et al. The functional microdomain in transmembrane helices 2 and 7 regulates expression, activation, and coupling pathways of the gonadotropin- releasing hormone receptor. J Biol Chem. 1999;274:28880-28886.

34. Xu W, Ozdener F, Li JG, et al. Functional role of the spatial proximity of Asp2.50(114) in TMH2 and Asn7.49(332) in TMH7 of the m opioid receptor. FEBS Lett. 1999;447:318-324.

35. Decaillot FM, Befort K, Filliol D, Yue S, Walker P, Kieffer BL. Opioid receptor random mutagenesis reveals a mechanism for G protein-coupled receptor activation. Nat Struct Biol. 2003;10:629-636.

36. Janz JM, Farrens DL. Rhodopsin activation exposes a key hydrophobic binding site for the transducin alpha-subunit $\mathrm{C}$ terminus. J Biol Chem. 2004;279:29767-29773.

37. Shapiro DA, Kristiansen K, Weiner DM, Kroeze WK, Roth BL. Evidence for a model of agonist-induced activation of 5-hydroxytryptamine $2 \mathrm{~A}$ serotonin receptors that involves the disruption of a strong ionic interaction between helices 3 and $6 . \mathrm{J}$ Biol Chem. 2002;277:11441-11449.

38. Kroeze WK, Kristiansen K, Roth BL. Molecular biology of serotonin receptors structure and function at the molecular level. Curr Top Med Chem. 2002;2:507-528.

39. Meng EC, Bourne HR. Receptor activation: what does the rhodopsin structure tell us? Trends Pharmacol Sci. 2001;22:587-593.

40. Gerber BO, Meng EC, Dotsch V, Baranski TJ, Bourne HR. An activation switch in the ligand binding pocket of the $\mathrm{C} 5 \mathrm{a}$ receptor. J Biol Chem. 2001;276:3394-3400.

41. Ghanouni P, Steenhuis JJ, Farrens DL, Kobilka BK. Agonistinduced conformational changes in the G-protein-coupling domain of the beta 2 adrenergic receptor. Proc Natl Acad Sci USA. 2001;98:5997-6002.

42. Ballesteros JA, Jensen AD, Liapakis G, et al. Activation of the beta 2 -adrenergic receptor involves disruption of an ionic lock between the cytoplasmic ends of transmembrane segments 3 and 6. J Biol Chem. 2001;276:29171-29177.

43. Gether U. Uncovering molecular mechanisms involved in activation of G protein-coupled receptors. Endocr Rev. 2000;21:90-113.

44. Gether U, Asmar F, Meinild AK, Rasmussen SG. Structural basis for activation of G-protein-coupled receptors. Pharmacol Toxicol. 2002;91:304-312.

45. Palczewski K, Kumasaka T, Hori T, et al. Crystal structure of rhodopsin: a G-protein coupled receptor. Science. 2000;289:739-745.

46. Okada T, Ernst OP, Palczewski K, Hofmann KP. Activation of rhodopsin: new insights from structural and biochemical studies. Trends Biochem Sci. 2001;26:318-324.
47. Stenkamp RE, Teller DC, Palczewski K. Crystal structure of rhodopsin: a G-protein-coupled receptor. ChemBioChem. 2002;3:963-967.

48. Filipek S, Stenkamp RE, Teller DC, Palczewski K. G proteincoupled receptor rhodopsin: a prospectus. Annu Rev Physiol. 2003;65:851-879.

49. Fritze O, Filipek S, Kuksa V, Palczewski K, Hofmann KP, Ernst OP. Role of the conserved NPxxY(x)5,6F motif in the rhodopsin ground state and during activation. Proc Natl Acad Sci USA. 2003;100:2290-2295.

50. Kalatskaya I, Schussler S, Blaukat A, et al. Mutation of tyrosine in the conserved NPXXY sequence leads to constitutive phosphorylation and internalization, but not signaling, of the human B2 bradykinin receptor. J Biol Chem. 2004;279:31268-31276.

51. Ballesteros JA, Weinstein H. Integrated methods for the construction of three-dimensional models and computational probing of structure-function relations in G protein-coupled receptors. In: Sealfon SC, ed. Receptor Molecular Biology. San Diego, CA: Academic Press; 1995:366-428.

52. Lin SW, Sakmar TP. Specific tryptophan UV-absorbance changes are probes of the transition of rhodopsin to its active state. Biochemistry. 1996;35:11149-11159.

53. Shi L, Javitch JA. The second extracellular loop of the dopamine D2 receptor lines the binding-site crevice. Proc Natl Acad Sci USA. 2004; 101:440-445.

54. Singh R, Hurst DP, Barnett-Norris J, Lynch DL, Reggio PH, Guarnieri F. Activation of the cannabinoid CB1 receptor may involve a W6 48/F3 36 rotamer toggle switch. J Pept Res. 2002;60:357-370.

55. Shi L, Liapakis G, Xu R, Guarnieri F, Ballesteros JA, Javitch JA. Beta2 adrenergic receptor activation: modulation of the proline kink in transmembrane 6 by a rotamer toggle switch. J Biol Chem. 2002;277:40989-40996.

56. McAllister SD, Hurst DP, Barnett-Norris J, Lynch D, Reggio PH, Abood ME. Structural mimicry in class A GPCR rotamer toggle switches: the importance of the F3.36(201)/W6.48(357) interaction in cannabinoid CB1 receptor activation. $J$ Biol Chem. 2004;279:48024-48037.

57. McAllister SD, Rizvi G, Anavi-Goffer S, et al. An aromatic microdomain at the cannabinoid $\mathrm{CB}(1)$ receptor constitutes an agonist/ inverse agonist binding region. J Med Chem. 2003;46:5139-5152.

58. Gay EA, Urban JD, Nichols DE, Oxford GS, Mailman RB. Functional selectivity of $\mathrm{D} 2$ receptor ligands in a Chinese hamster ovary $\mathrm{hD} 2 \mathrm{~L}$ cell line: evidence for induction of ligand-specific receptor states. Mol Pharmacol. 2004;66:97-105.

59. Mottola DM, Kilts JD, Lewis MM, et al. Functional selectivity of dopamine receptor agonists. 1. Selective activation of postsynaptic dopamine D2 receptors linked to adenylate cyclase. J Pharmacol Exp Ther. 2002;301:1166-1178.

60. Ghanouni P, Gryczynski Z, Steenhuis JJ, et al. Functionally different agonists induce distinct conformations in the $\mathrm{G}$ protein coupling domain of the beta 2 adrenergic receptor. J Biol Chem. 2001;276:24433-24436.

61. McLaughlin JN, Shen L, Holinstat M, Brooks JD, Dibenedetto E, Hamm HE. Functional selectivity of $G$ protein signaling by agonist peptides and thrombin for the protease-activated receptor-1. J Biol Chem. 2005;280:25048-25059.

62. Vilardaga JP, Steinmeyer R, Harms GS, Lohse MJ. Molecular basis of inverse agonism in a $\mathrm{G}$ protein-coupled receptor. Nature Chem Biol. 2005;1:25-28. 
The AAPS Journal 2006; 7 (4) Article 85 (http://www.aapsj.org).

63. Javitch JA, Ballesteros JA, Weinstein H, Chen J. A cluster of aromatic residues in the sixth membrane-spanning segment of the dopamine $\mathrm{D} 2$ receptor is accessible in the binding site crevice. Biochemistry. 1998;37:998-1006.

64. Javitch JA, Ballesteros JA, Weinstein H, Chen J. A cluster of aromatic residues in the sixth membrane-spanning segment of the dopamine D2 receptor is accessible in the binding-site crevice. Biochemistry. 1998;37:998-1006.

65. Filizola M, Hassan SA, Artoni A, Coller BS, Weinstein H. Mechanistic insights from a refined 3-dimensional model of integrin alphaIIbbeta3. J Biol Chem. 2004;279:24624-24630.

66. Liggett SB. Update on current concepts of the molecular basis of beta2-adrenergic receptor signaling. J Allergy Clin Immunol. 2002;110:S223-S227.

67. McAllister SD, Hurst DP, Barnett-Norris J, Lynch D, Reggio PH, Abood ME. Structural mimicry in class A G protein-coupled receptor rotamer toggle switches: the importance of the F3.36(201)/W6.48(357) interaction in cannabinoid CB1 receptor activation. $J$ Biol Chem. 2004;279:48024-48037.

68. Mehler EL, Periole X, Hassan SA, Weinstein H. Key issues in the computational simulation of GPCR function: representation of loop domains. J Comput Aided Mol Des. 2002;16:841-853.

69. Visiers I, Hassan SA, Weinstein H. Differences in conformational properties of the second intracellular loop (IL2) in 5HT(2C) receptors modified by RNA editing can account for $\mathrm{G}$ protein coupling efficiency. Protein Eng. 2001;14:409-414.

70. McGrew L, Price RD, Hackler E, Chang MS, Sanders-Bush E. RNA editing of the human serotonin 5-HT2C receptor disrupts transactivation of the small G-protein RhoA. Mol Pharmacol. 2004;65:252-256.

71. Niswender CM, Copeland SC, Herrick-Davis K, Emeson RB, Sanders-Bush E. RNA editing of the human serotonin 5-hydroxytryptamine $2 \mathrm{C}$ receptor silences constitutive activity. $\mathrm{J}$ Biol Chem. 1999;274:9472-9478.

72. Hassan SA, Mehler EL, Zhang D, Weinstein H. Molecular dynamics simulations of peptides and proteins with a continuum electrostatic model based on screened Coulomb potentials. Proteins.

2003;51:109-125.

73. Hassan SA, Mehler EL, Weinstein H. Structure calculations of protein segments connecting domains with defined secondary structure: a simulated annealing monte carlo combined with biased scaled collective variables technique. In: Hark K, Schlick T, eds. Lecture Notes in Computational Science and Engineering. New York, NY: Springer Verlag, Ag; 2002:197-231.

74. Sankararamakrishnan R, Weinstein H. Surface tension parameterization in molecular dynamics simulations of a phospholipidbilayer membrane: calibration and effects. J Phys Chem B. 2004;108:11802-11811.

75. Fong SL, Tsin AT, Bridges CD, Liou GI. Detergents for extraction of visual pigments: types, solubilization, and stability. Methods Enzymol. 1982;81:133-140.

76. Liang Y, Fotiadis D, Filipek S, Saperstein DA, Palczewski K, Engel A. Organization of the $\mathrm{G}$ protein-coupled receptors rhodopsin and opsin in native membranes. J Biol Chem. 2003;278:21655-21662.

77. Sankararamakrishnan R, Weinstein H. Molecular dynamics simulations predict a tilted orientation for the helical region of dynorphin A(1-17) in dimyristoylphosphatidylcholine bilayers. Biophys J. 2000;79:2331-2344.
78. Sankararamakrishnan R, Weinstein H. Positioning and stabilization of dynorphin peptides in membrane bilayers: the mechanistic role of aromatic and basic residues revealed from comparative MD simulations. J Phys Chem B. 2002;106:209-218.

79. Tieleman DP, Berendsen HJ, Sansom MS. An alamethicin channel in a lipid bilayer: molecular dynamics simulations. Biophys $J$. 1999;76:1757-1769.

80. Marrink SJ, Berger O, Tieleman P, Jahnig F. Adhesion forces of lipids in a phospholipid membrane studied by molecular dynamics simulations. Biophys J. 1998;74:931-943.

81. Petrache HI, Dodd SW, Brown MF. Area per lipid and acyl length distributions in fluid phosphatidylcholines determined by (2)H NMR spectroscopy. Biophys J. 2000;79:3172-3192.

82. Bock G, Goode JA, eds. In silico simulation of biological processes, Novartis Foundation Symposium 247. In: Novartis Foundation Symposium. Vol 247. Chichester, UK: John Wiley \& Sons; 2002:262.

83. Fall C, Marland ES, Wagner JM, Tyson JJ. Computational Cell Biology. New York, NY: Springer Verlag; 2002.

84. Brown KS, Hill CC, Calero GA, et al. The statistical mechanics of complex signaling networks: nerve growth factor signaling. Phys Biol. 2004;1:184-195.

85. Barrios-Rodiles M, Brown KR, Ozdamar B, et al. High-throughput mapping of a dynamic signaling network in mammalian cells. Science. 2005;307:1621-1625.

86. Loew LM. The Virtual Cell project. Novartis Found Symp. 2002;247:151-160. Discussion 160-161, 198-206, 244-252.

87. Loew LM, Schaff JC. The Virtual Cell: a software environment for computational cell biology. Trends Biotechnol. 2001;19:401-406.

88. Sauro HM, Kholodenko BN. Quantitative analysis of signaling networks. Prog Biophys Mol Biol. 2004;86:5-43.

89. Kurrasch-Orbaugh DM, Parrish JC, Watts VJ, Nichols DE. A complex signaling cascade links the serotonin2A receptor to phospholipase A2 activation: the involvement of MAP kinases. J Neurochem. 2003;86:980-991.

90. Kurrasch-Orbaugh DM, Watts VJ, Barker EL, Nichols DE. Serotonin 5-hydroxytryptamine $2 \mathrm{~A}$ receptor-coupled phospholipase C and phospholipase A2 signaling pathways have different receptor reserves. J Pharmacol Exp Ther. 2003;304:229-237.

91. Akin D, Manier DH, Sanders-Bush E, Shelton RC. Decreased serotonin 5-HT2A receptor-stimulated phosphoinositide signaling in fibroblasts from melancholic depressed patients. Neuropsychopharmacology. 2004;29:2081-2087.

92. Conn PJ, Sanders-Bush E. Selective 5HT-2 antagonists inhibit serotonin stimulated phosphatidylinositol metabolism in cerebral cortex. Neuropharmacology. 1984;23:993-996.

93. Roth BL, Nakaki T, Chuang DM, Costa E. Aortic recognition sites for serotonin (5HT) are coupled to phospholipase $\mathrm{C}$ and modulate phosphatidylinositol turnover. Neuropharmacology. 1984;23:1223-1225.

94. Sanders-Bush E, Tsutsumi M, Burris KD. Serotonin receptors and phosphatidylinositol turnover. Ann N Y Acad Sci. 1990; 600:224-235.

95. Berg KA, Maayani S, Goldfarb J, Scaramellini C, Leff P, Clarke WP. Effector pathway-dependent relative efficacy at serotonin type $2 \mathrm{~A}$ and $2 \mathrm{C}$ receptors: evidence for agonist-directed trafficking of receptor stimulus. Mol Pharmacol. 1998;54:94-104. 


\section{The AAPS Journal 2006; 7 (4) Article 85 (http://www.aapsj.org).}

96. Bhalla US, Ram PT, Iyengar R. MAP kinase phosphatase as a locus of flexibility in a mitogen-activated protein kinase signaling network. Science. 2002;297:1018-1023.

97. Weng G, Bhalla US, Iyengar R. Complexity in biological signaling systems. Science. 1999;284:92-96.
98. Bruggeman FJ, Kholodenko BN. Modular interaction strengths in regulatory networks: an example. Mol Biol Rep. 2002;29:57-61.

99. Markevich NI, Hoek JB, Kholodenko BN. Signaling switches and bistability arising from multisite phosphorylation in protein kinase cascade. J Cell Biol. 2004;164:353-359. 